\title{
A clinical evaluation of the applanation pneumatonograph
}

\author{
M. R. JAIN* AND V. J. MARMION \\ From the Bristol Eye Hospital, Bristol
}

The applanation pneumatonograph (PTG) is a machine which can measure the intraocular pressure, aqueous humour dynamics, and the ocular pulse. It has been developed principally by Langham and McCarthy (1968), Walker and Litovitz (1972), and Walker and Langham (1975). The instrument is a combination of a pneumatic and an electronic system. The pneumatic part of the instrument measures the intraocular pressure with the help of a small and delicate sensor that applanates the cornea and floats on an almost frictionless air bearing. The electronic part converts these measurements into electronic signals, which can be shown on the digital display or recorded on a continuous chart, providing a permanent record of the intraocular pressure, pulse, or tonography.

The merits of the instrument are threefold. It is portable and provides a continuous recording of the intraocular pressure in either the supine or sitting position. Secondly, it is possible to do tonography with easy calculation of the facility of outflow, and thirdly, a recording of the ocular pulse can be obtained. An essential element of the PTG is the sensor, see Fig. I. This is made of plastic and covered with a thin silastic membrane which makes contact with the cornea. A gas, dichloro-difloromethane $\left(\mathrm{CCl}_{2} \mathrm{~F}_{2}\right)$ is passed into the system through a solenoid valve. The pressure thrusts the piston and sensor forwards causing the membrane to applanate the cornea. The pressure continues to increase until it is equal to the intraocular pressure. Since the sensor-piston is freefloating, a balance is achieved between the intraocular pressure on the one side and the gas pressure on the other, and a measurement of the intraocular pressure can thus be made. As long as the piston is allowed to float, the pressure is registered on the chart and on the digital display. A weight (Fig. I) is applied above the disc in tonographic procedures. The whole instrument is shown in Fig. 2.

- Reader in Ophthalmology, Ravinder Nath Tagore, Medical College, Udaipur, India, currently a Commonwealth Fellow, Bristol Eye Hospital

Address for reprints: V. J. Marmion, FRCS, 73 Pembroke Road, Clifton, Bristol BS8 3 DW

\section{Material and methods}

To compare the recordings of the PTG with those of the Goldmann tonometer, two groups of patients were examined. The first comprised 20 normal subjects (40 eyes) with an age range of 50 to 70 years, and the second a group of 35 glaucomatous patients (40 eyes) with an age range of 55 to 80 years.

The appropriate adjustments were made to the controls of the PTG. The eyes were anaesthetized with a 0.4 per cent solution of benoxinate hydrochloride. The patient was seated erect in a chair and tonometry was performed with the patient looking straight ahead. The sensor was applied to the apical zone of the cornea for about 5 seconds. Correct applanation was confirmed by a gentle whistle, and the tension was shown on the digital display and registered on the graph paper (Fig. 3). To determine the degree of reproducibility, two consecutive readings were performed at a $5 \mathrm{~min}$ interval. The patient was then given conventional applanation tonometry on the Haag-Streit slit lamp with a Goldmann tonometer. Both instruments were calibrated periodically, particularly the PTG, during testing.

To avoid any disturbance of the results, the ocular pulse was recorded in normal eyes 15 min after taking the intraocular pressure measurements. After necessary adjustment, the sensor was re-applied to the cornea and the ocular pulse was recorded (Fig. 4), the amplitude being calculated in $\mathrm{mmHg}$.

\section{Results}

The comparative recordings of the intraocular pressure by applanation tonometry and the PTG in 40 normal eyes are shown in Fig. 5. The mean intraocular pressure was $18.25 \pm 0.25 \mathrm{mmHg}$ with the PTG, and $17.5 \pm 0.19 \mathrm{mmHg}$ with the Gold-

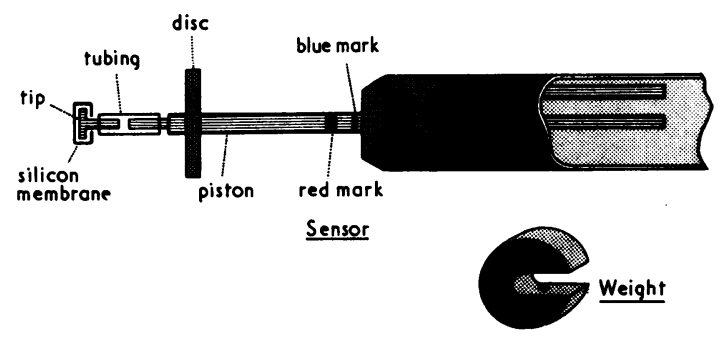

FIG. I Sensor and weight 


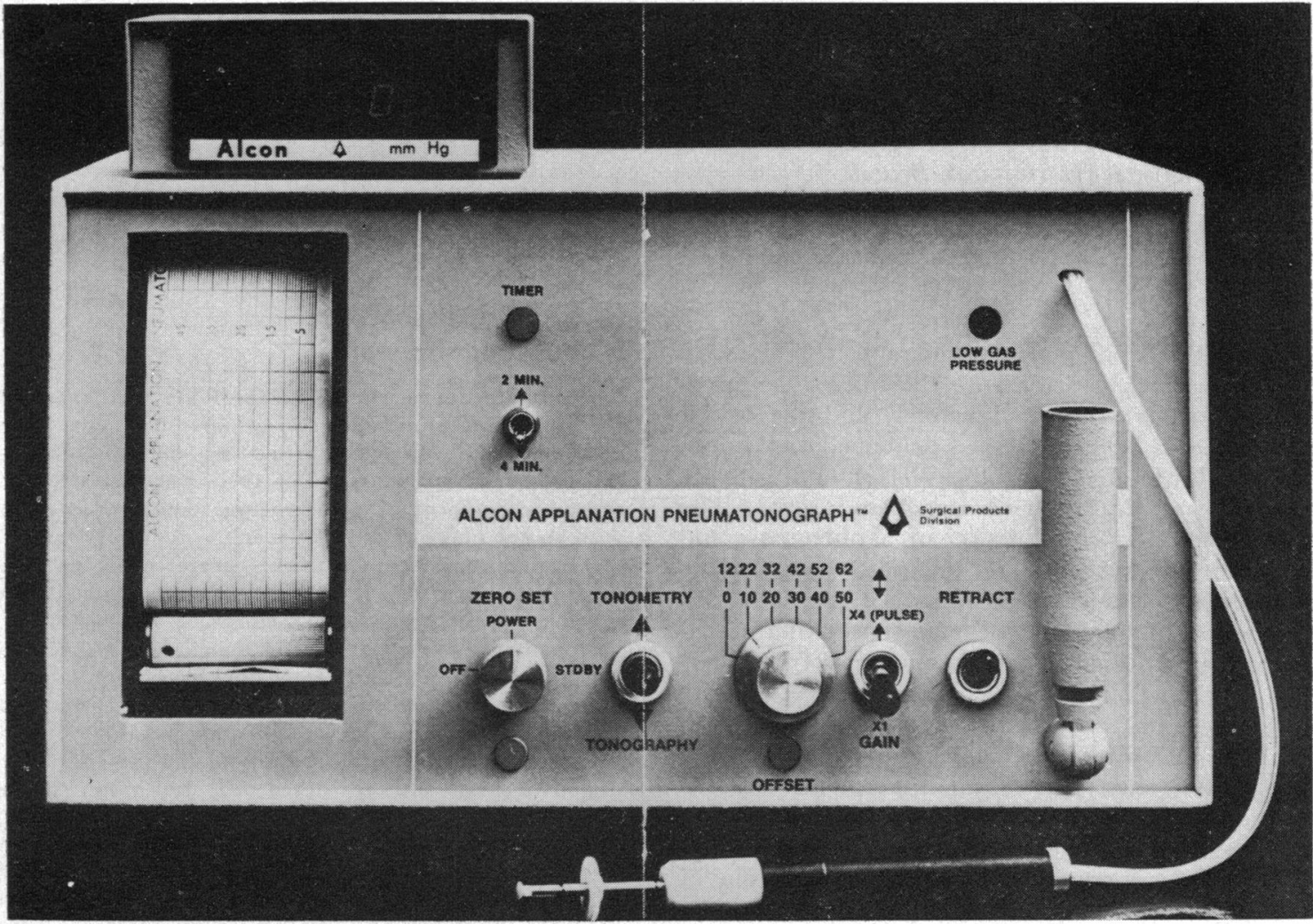

FIG. 2 Alcon applanation pneumatonograph

mann applanation tonometer. The PTG gave higher recordings than the Goldmann applanation tonometer. Standard deviation of readings with the PTG was 1.58 and with the Goldmann tonometer $I \cdot 17$, with a correlation coefficient of 0.871 .

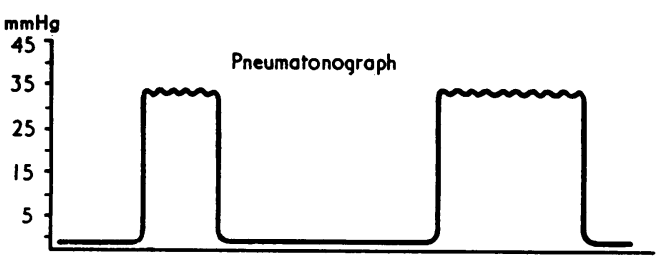

FIG. 3 Drawing of typical pneumatonographic recording

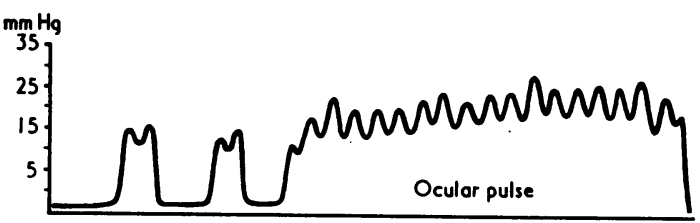

FIG. 4 Drawing of ocular pulse recording
Fig. 6 shows that 32.5 per cent of the normal and 30 per cent of glaucomatous eyes had the same $\frac{O}{0}$. readings with both the PTG and applanation :tonometer; however, 60 per cent had higher 3 . readings with the PTG. The maximum difference 8 was $2.5 \mathrm{mmHg}$ in normal eyes and $4.5 \mathrm{mmHg}$ in glaucomatous eyes.

Repeated measurements with the PTG at $5 \mathrm{~min}$ intervals in 40 normal eyes gave exactly similar readings in 70 per cent, higher in 20 per cent, and lower in ro per cent.

The mean intraocular pressure in glaucomatous $N$ eyes was $35.75 \pm \mathrm{r} \cdot 25$ and $34.5 \pm 0.75 \mathrm{mmHg}$ with PTG and Goldmann tonometry, respectively; the difference was $\mathrm{r} \cdot 25 \mathrm{mmHg}$.

In normal patients the mean ocular pulse was $3.25 \pm 0.21 \mathrm{mmHg}$ (range of 2.5 to 4.5 ); the standard deviation was 0.35 .

\section{Discussion}

Goldmann applanation tonometry has been an accurate method of measurement of intraocular pressure and the results have been shown to agree with manometrically-determined pressures. The 


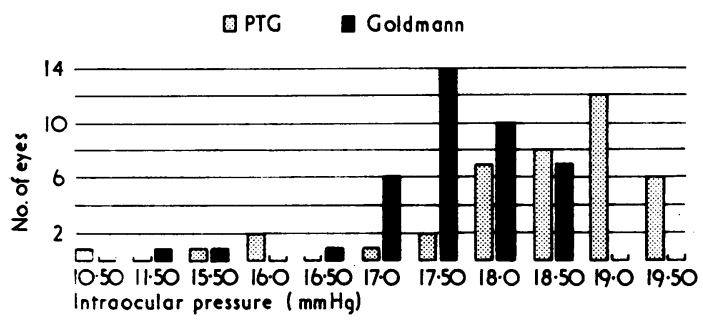

FIG. 5 Intraocular pressure in 40 normal eyes with PTG and Goldmann tonometer

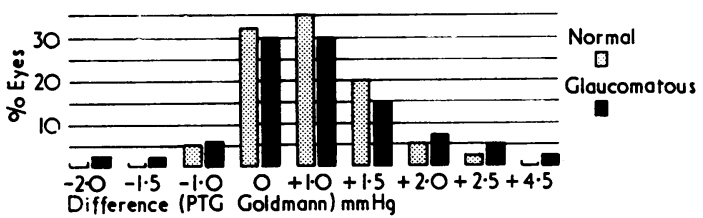

FIG. 6 Distribution of difference between intraocular pressure in normal and glaucomatous eyes, obtained with PTG and Goldmann tonometer

pneumatonograph gives a comparable accuracy in the recording of intraocular pressures and has the advantage of being reproducible in different postures; the influence of posture on intraocular pressure can, therefore, be more exactly determined. Applanation pneumatonography is more versatile as it is portable and does not require a slit lamp or fluorescein, and a permanent written record is available.

Our study shows that in normal and glaucomatous eyes the difference was small: $0.75 \mathrm{mmHg}$ in normal and $1.25 \mathrm{mmHg}$ in glaucomatous eyes. The mean difference in our series is slightly less than that reported by Quigley and Langham (1975) in roo normal eyes. The correlation coefficient of $0.87 \mathrm{I}$ is highly significant suggesting a good agreement between the PTG and the Goldmann readings. It must, however, be noted that the difference between the PTG and the Goldmann readings tends to increase with the higher pressures and particularly in glaucomatous cases.
Moses and Liu (1968) showed that there was a mean pressure difference of $2 \mathrm{mmHg}$ in 35 per cent of eyes after repeated Goldmann tonometry.

As stated, repeated measurements showed no difference in 70 per cent of cases and only a slight difference in the remainder, suggesting that the external force applied in this technique is comparatively less than with the Goldmann tonometer. This finding makes the PTG more acceptable for dose-response studies where frequent readings at short intervals are essential.

The mean intraocular pressure in the normal patients examined compares poorly with normal pressures as reported by Tierney and Rubin (1966), Becker and Shaffer (196r), and Armaly and Salamoun (1963), but reasonably well with recent studies of Quigley and Langham (1975) (Table). The variation with earlier authors is probably due to the different age group examined. Our normal cases were between 50 and 70 years of age and, therefore, are more comparable with the glaucomatous group, and representative of a normal ageing population.

The amplitude of ocular pulse as analysed in 40 normal eyes had a mean value of $3.25 \pm 0.21$ $\mathrm{mmHg}$ (range of 2.5 to 4.5 ). This is close to that reported by Bynke (1968), Best and Rogers (1974), and Quigley and Langham (1975).

It was, however, observed that, in cases with an ocular pulse of more than $3 \mathrm{mmHg}$, visual estimation of the point of inner ring contact in Goldmann tonometry introduces an important variation in readings, whereas the PTG provides a graphic recording of systolic and diastolic pulse pressure. Moreover, its readings do not have the potential inaccuracy of visual mean estimation nor the possible bias of a hand-operated scale as with the Goldmann tonometer.

An important advantage of the PTG over the Goldmann lies in its ability to measure intraocular pressure independent of posture. This provides a simpler means of studying the postural effects of intraocular pressure on individual eyes. The mean pressure increment in normal eyes, as noted by

Table Comparison of means and standard deviations of applanation readings

\begin{tabular}{|c|c|c|c|c|c|c|c|}
\hline \multirow{2}{*}{$\begin{array}{l}\text { Method } \\
\text { Authors } \\
\text { Date }\end{array}$} & \multicolumn{2}{|l|}{$P T G$} & \multicolumn{5}{|c|}{ Goldmann tonometry } \\
\hline & $\begin{array}{l}\text { Fain and } \\
\text { Marmion } \\
1975\end{array}$ & $\begin{array}{l}\text { Quigley and } \\
\text { Langham } \\
\text { I975 }\end{array}$ & $\begin{array}{l}\text { Tierney and } \\
\text { Rubin } \\
\text { 1966 }\end{array}$ & $\begin{array}{l}\text { Becker and } \\
\text { Shaffer } \\
\text { I } 96 \mathrm{I}\end{array}$ & $\begin{array}{l}\text { Armaly and } \\
\text { Salamoun } \\
1963\end{array}$ & $\begin{array}{l}\text { Quigley and } \\
\text { Langham } \\
\text { 1975 }\end{array}$ & $\begin{array}{l}\text { Jain and } \\
\text { Marmion } \\
\text { I } 975\end{array}$ \\
\hline $\begin{array}{l}\text { Mean } \\
\text { Standard } \\
\quad \text { deviation }\end{array}$ & $\begin{array}{l}18 \cdot 25 \pm 0.25 \\
1 \cdot 59\end{array}$ & $\begin{array}{l}21 \cdot 50 \pm 0 \cdot 81 \\
2 \cdot 83\end{array}$ & $\begin{array}{r}16.23 \\
2.50\end{array}$ & $\begin{array}{l}15 \cdot 40 \\
-\end{array}$ & $\begin{array}{l}14.73 \\
-\end{array}$ & $\begin{array}{l}20.2 \pm 1 \cdot 0 \\
-\end{array}$ & $\begin{array}{l}17.50 \pm 0.19 \\
1.19\end{array}$ \\
\hline
\end{tabular}


Langham (1974), Armaly and Salamoun (1963), and Langham and McCarthy (1968), was 2.I, $2 \cdot 63$, and $\mathrm{x} \cdot 78 \mathrm{mmHg}$, respectively. The postural difference in pressure is of significance in the diagnosis of borderline cases of glaucoma, particularly those where the postural element is marked.

The correct application of the sensor to the cornea is confirmed by a whistle emitted from the PTG. The sensor tip is generally applied to the apical zone of the cornea for convenience and quick results, but it can also be applied to paracentral or para-apical zones with satisfactory results. This fact was confirmed in a few of our cases and we were successful in determining the intraocular pressure in two cases of central corneal ectasia where neither Goldmann nor Schiötz tonometry was possible. Its comparatively gentle touch and ability to record pressure in any position, without the use of fluorescein, enable the recording of pressures in the immediate postoperative period and in patients wearing soft contact lenses.

\section{Summary}

The applanation pneumatonograph combines pneumatic and electronic systems. It is used for measuring intraocular pressure, aqueous humour dynamics, and ocular pulsation.

In the present study the PTG and the Goldmann tonometer have been used to measure the intraocular pressure in 40 normal and 40 glaucomatous eyes. It has been found that the results of the two instruments correlate well. The PTG readings have, generally, been found to be higher with a mean difference of $0.75 \mathrm{mmHg}$ in the normal and $\mathbf{I} \cdot 25 \mathrm{mmHg}$ in the glaucomatous eye.

The mean ocular pulse as determined in normal eyes was $3.25 \pm 0.2 \mathrm{I} \mathrm{mmHg}$.

\section{References}

ARMAly, M. F., and Salamoun, s. G. (1963) Arch. Ophthal., 70, 603

BECKER, B., and SHAFFER, R. N. (I96r) 'Diagnosis and Therapy of Glaucoma'. Mosby, St Louis BEST, M., and ROGERS, R. (1974) Arch. Ophthal., 92, 54

BYNKE, H. G. (1968) Acta ophthal (Kbh.), 46, I I 35

LANGHAM, M. E. (1974) International Congress of Ophthalmology, Albi, France

- and MCCARTHY, E. (1968) Arch. Ophthal., 79, 389

MOSES, R. A., and LIU, C. H. (1968) Amer. F. Ophthal., 66, 89

QUigley, H. A., and LANGHAM, M. E. (1975) Ibid., 80, 266

TIERNEY, J. P., and RUBIN, M. L. (I966) Ibid., 66, 263

WALKER, R. E., and LANGHAM, M. E. (1975) Exp. Eye Res., 20, I

- and LITOVITZ, T. L. (1972) Ibid., I3, 14 